\title{
The Hysteroid and Obsessoid Personalities, Depression and Suicidality
}

\author{
David Lester* \\ Stockton University, School of Social and Behavioral \\ Sciences, USA \\ *Corresponding author: David Lester, Stockton \\ University, School of Social and Behavioral Sciences, \\ Galloway, NewJ ersey, USA
}

Received: J anuary 22, 2021; Accepted: February 24, 2021; Published: March 03, 2021

\begin{abstract}
This study was designed to explore the associations between scores on the hysteroid/obsessoid personality scale, depression scores, and suicidal behavior. In a study of 101 undergraduate students, using the Hysteroid/ Obsessoid Questionnaire (HQQ) and the short form of the Beck Depression Inventory (BDI-13), hysteroid-obsessiod personality scores were negatively associated with depression scores but not with a history of suicidal ideation or attempts. It is suggested that separate measures of the hysteroid and obsessive personalities may be more useful for predicting depression and suicidality.
\end{abstract}

Keywords: Hysteroid personality; Obsessoid personality; Depression; Suicidality; Students; USA

\section{Introduction}

Caine and Hawkins [1], Hope and Caine [2] devised a Hysteroid/ Obsessoid Questionnaire (HOQ), the aim of which was to measure this dimension of pathology. Caine and Hawkins hypothesized that these two types of personality (hysteroid and obsessoid) were the poles of a single dimension. The constructs of hysteroid and obsessoid are similar to Angyal's [3] constructs of the pattern of vicarious living and the pattern of noncommitment, respectively, since Angyal proposed that hysterics had the pattern of vicarious living while those with anxiety disorders had the pattern of noncommitment. In Angyal's theory, obsessive-compulsives show the pattern of noncommitment while hysterics show the pattern of vicarious living $[4,5]$. Similarly, the constructs of hysteroid and obsessoid are similar to the constructs of hysterics and dysthymics in Eysenck's theory of personality. For Eysenck, hysterics were viewed as neurotic extraverts whereas dysthymics were viewed as neurotic introverts.

Goldney [6] reviewed studies using the HOQ with samples of attempted suicides. Vinoda [7] found a non-significant tendency for attempted suicides to be obsessoid, as did Eastwood et al. [8]. Murthy found that the less medically serious attempters tended to be more hystyeroid. In his own study, Goldney also found that young women who attempted suicide did not differ from psychiatric controls in HOP scores. However, those making less medically serious attempts did tend toward being hysteroid. No more recent studies were located, and no studies on the HOQ and depression.

In studies of clinical samples, no reports of an increased risk of suicidal ideation or behavior in those with hysterical personality disorder were identified, perhaps attesting to la belle indifference, which is thought to characterize those with hysterical personality disorder. However, suicidal ideation and behavior does appear to be more common in those with obsessive-compulsive disorder. A recent meta-analysis by Pellegrini, et al., [9] found that roughly, 10\% of patients with obsessive-compulsive disorder make lifetime suicide attempts and 50\% have lifetime suicidal ideation.

Research has been conducted using scales to assess the obsessive- compulsive personality. In a study of 87 Kuwaiti undergraduate students, Lester and Abdel-Khalek [10] found that scores on the Arabic Obsessive Compulsive Scale (ASOC: [11]) and on the Maudsley Obsessional Compulsive Inventory [12] were associated with depression scores but not with past suicidal ideation. In a study of 111 Iranian psychiatric outpatients, Dadfar, Abdel-Khalek and Lester [13] also found that scores on the ASOC, were associated with depression scores. The present study was designed to explore the associations between scores on Caine's measure of the hysteroidobsessoid personality with depression and suicidal behavior.

\section{Methods}

\section{Participants}

The participants were 101 undergraduates enrolled in a psychology course. There were 73 women and 28 men, with a mean age of 21.2 yrs., $S D=3.5$, median 20 and range 18-40. Ethical approval was obtained from the Institutional Review Board at Stockton University, USA, for the study.

\section{Measures}

Hysteroid-Obsessoid Questionnaire (HOQ): This trait was assessed using a 48-item scale developed by Caine [14]. A typical item is "I like to wear eye-catching clothes." Scores on the scale were associated with psychiatric classification of patients [2] and with extraversion scores [1]. Inter-item correlations were reported to be high [14]. Caine and Hawkins [1] did not present modern tests of the reliability of the scale, although the test-retest reliability after 6 weeks of therapy was 0.77 , but they did find evidence for its validity, including correlations with clinician ratings $(\mathrm{r}=0.68)$ and with scores on a measure of extraversion $(r=0.84)$ [15].

The short form of the Beck Depression Inventory (BDI-13): The BDI-13, developed by Beck and Beck [16], has 13 items and has good construct validity $(\mathrm{r}=0.94)$ with the 21 -item long form $[17,18]$. The 13-items each have four levels of response. A typical item is "I do not feel sad, I feel sad, I am sad all of the time and I can't snap out of it, and I am so sad or unhappy that I can't stand it". Each item is scored on a scale of 0 to 3 , and respondents choose one response, giving a 
Table 1: Multiple regressions to predict depression and suicidality.

\begin{tabular}{|c|c|c|c|c|c|}
\hline & \multirow{3}{*}{$\begin{array}{c}\begin{array}{c}\text { Linear regression } \\
\text { depression }\end{array} \\
\text { Beta }\end{array}$} & \multicolumn{4}{|c|}{ Binary logistic regression } \\
\hline & & \multicolumn{2}{|c|}{$\begin{array}{l}\text { Suicidal } \\
\text { ideation }\end{array}$} & \multicolumn{2}{|c|}{$\begin{array}{c}\text { Suicide } \\
\text { attempts }\end{array}$} \\
\hline & & B & SE & B & SE \\
\hline $\begin{array}{l}\text { Hysteroid- } \\
\text { obsessoid }\end{array}$ & $-0.227^{\star}$ & +0.04 & 0.047 & +0.007 & 0.073 \\
\hline Age & $+0.208^{*}$ & +0.14 & 0.091 & +0.216 & $0.097^{*}$ \\
\hline Sex & -0.129 & -0.489 & 0.52 & -1.102 & 0.975 \\
\hline $\mathbf{R}^{2}$ & 0.107 & 0.06 & & & 0.142 \\
\hline
\end{tabular}

total score ranging from 0 to 39: normal (0-3); mild depression (4-7); mild to average depression (8-11); average depression (12-15); and severe depression (16-39) [19]. Cronbach's alphas ranged from 0.78 to $0.97[17,18], .89$ to $.94[19,20]$, and 0.85 [21]. Correlations between scores on the BDI-13 and scores on the Beck Suicide Ideation Scale (BSIS), were 0.49, 0.35 with the Beck Hopelessness Scale (BHS), 0.79 with the Kessler Psychological Distress Scale (K10), 0.75 with the General Health Questionnaire-12 (GHQ-12), and 0.62 with the Death Obsession Scale (DOS) [21]. The participants were also asked to respond to "I have had thoughts of killing myself in the past" and "In the past, I have attempted suicide."

\section{Results}

The mean score for the HOQ was 24.30 ( $\mathrm{SD}=4.63$, range 12-38) and the Cronbach alpha was 0.55 . The mean scores for BDI-13 was $5.06(\mathrm{SD}=4.89$, range $0-20)$ and the Cronbach alpha was 0.86 . Thirtynine percent of the students reported a history of suicidal ideation and $12 \%$ a history of attempting suicide.

Hysteroid-obsessoid scores were associated negatively with depression scores $(\mathrm{r}=-0.24$, two-tailed $\mathrm{p}<0.01)$, but not with a history of suicidal ideation or attempts (point-biserial $r=0.08$ and -0.01 , respectively). Partial correlations controlling for age and sex did not change the results.

In multiple regressions, depression scores were predicted by age and HOQ scores, a history of suicide attempts was predicted only by age, and none of three variables predicted a history of suicidal ideation (Table 1).

\section{Discussion}

In the present study, hysteroid-obsessiod personality scores were negatively associated with depression scores but not with a history of suicidal ideation or attempts. These results support those reported by Lester and Abdel-Khalek [10] who found that measures of obsessivecompulsive tendencies were associated with depression but not prior suicidality, while Dadfar et al., [13] found that obsessive-compulsive scores were correlated with depression scores.

Looking at individuals with psychiatric diagnoses, personality disorders are one of risk factors for suicide attempts [22]. ObsessiveCompulsive Personality Disorder (OCPD) is a factor risk for nonlethal suicidal behavior [23]. OCP traits are correlated with mood instability and, in addition, OCPD traits, along with mood instability and negative mood, predict suicidal ideation and attempts [24,25]. Bowen et al., [26] found that OCP traits predict suicidal thoughts, and suicide attempts.
The present findings are limited by the cross-sectional design of the study, and the use of a non-clinical sample of college students with a limited age range and a preponderance of female participants. Furthermore, the present study was limited by the use of short forms of the assessment tools. The questions regarding suicidal ideations and behavior asked for lifetime suicidality rather than recent suicidality (in the past year). Finally, the sample was one of American undergraduate students, and studies in other cultural groups may produce different results.

The results of the present study suggest that it may be more useful for predicting depression and suicidal behavior to have separate measures of the hysteroid and obsessive personalities rather than a using a scale which assumes that the two personalities are opposite ends of a continuum.

\section{Conclusions}

The study found that the Caine measure of the hysteroidobsessoid personality predicted depression scores in a non-clinical sample, but not their history of suicidal ideation and behavior.

\section{References}

1. Caine TM, Hawkins LG. Questionnaire measures of the hysteroid/obsessoid component of personality. Journal of Consulting Psychology. 1963; 27: 206209.

2. Hope K, Caine TM. The Hysteroid Obsessoid Questionnaire: A new validation. British Journal of Social and Clinical Psychology. 1968; 7: 210-215.

3. Angyal A. Neurosis and treatment. New York: Wiley. 1965.

4. Lester D, Dench B. The holistic theory of Andras Angyal. Psychological Reports. 2011; 108: 213-216.

5. Lester. Theories of personality: A systems approach. Routledge. 1974.

6. Goldney RD. Are young women who attempt suicide hysterical?. British Journal of Psychiatry. 1981; 138: 141-146.

7. Vinoda KS. Personality characteristics of attempted suicides. British Journal of Psychiatry. 1966; 112: 1153-1150.

8. Eastwood MR, Henderson AS, Montgomery FM. Personality and parasuicide. Medical Journal of Australia. 1972; 170-175

9. Pellegrini L, Maietti E, Rucci P, Casadel G, Maina G, Fineberg NA, et al. Suicide attempts and suicidal ideation in patients with obsessive-compulsive disorder. Journal of Affective Disorders. 2020; 276: 1001-1021.

10. Lester D, Abdel-Khalek AM. Manic-depression, suicidality, and obsessivecompulsive tendencies. Psychological Reports. 1999; 85: 1100.

11. Abdel-Khalek AM. The development and validation of the Arabic Obsessivecompulsive Scale. European Journal of Psychological Assessment. 1998; 14: 146-158.

12. Hodgson RI, Rachman S. Obsessional-compulsive complaints. Behavior Research \& Therapy. 1977; 15: 389-395.

13. Dadfar M, Abdel-Khalek AM, Lester D. The Revised Arabic Scale of Obsession-Compulsion (ASOC): Validation with Iranian psychiatric outpatients. Mental Health, Religion \& Culture. 2020; 23: 274-288.

14. Caine TM. Personality and illness. Editors. In: Mittler PJ, the psychological assessment of mental and physical handicaps. London, UK: Methuen. 1973: 781-817.

15. Caine TM, Hope K. Manual of the Hysteroid-obsessoid Questionnaire. University of London Press. 1967.

16. Beck AT, Beck RW. Screening depressed patients in family practice. A rapid technique. Postgraduate Medicine. 1972; 52: 81-85.

17. Beck AT, Beamesderfer A. Assessment of depression: the depression 
inventory, In Psychological Measurements in Psychopharmacology: Modern Problems in Pharmacopsychiatry, Editor. In: Pichot P, Karger, Oxford, UK. 1974; 7: 151-169.

18. Beck AT, Rial WR, Rickels K. Short form of depression inventory: cross validation. Psychological Reports. 1974; 34: 1184-1186.

19. Dadsetan P, Mansour M. Mental Disorders, Roshd Publications, Tehran, Iran 1990.

20. Rajabi GhR. Psychometric properties of Beck Depression Inventory short form items (BDI-13). Journal of Iranian Psychologists. 2005; 1: 291-298.

21. Dadfar M, Kalibatseva Z. Psychometric properties of the Persian version of the short Beck Depression Inventory (BDI-13) with Iranian psychiatric outpatients. Scientifica. 2016; 2016: 8196463.

22. Ansell EB, Wright AG, Markowitz JC, Sanislow CA, Hopwood CJ, Zanarini $\mathrm{MC}$, et al. Personality disorder risk factors for suicide attempts over 10 years of follow-up. Journal of Personality Disorders. 2015; 6: 161-167.
23. Diaconu G, Turecki G. Obsessive-compulsive personality disorder and suicidal behavior: evidence for a positive association in a sample of depressed patients. Journal of Clinical Psychiatry. 2009; 70: 1551-1556.

24. Bowen R, Balbuena L, Baetz M, Marwaha S. Mood instability in people with obsessive compulsive disorder and obsessive-compulsive personality traits. Journal of Obsessive-Compulsive and Related Disorders. 2015a; 6: 108-113.

25. Bowen R, Balbuena L, Peters EM, Leuschen-Mewis C, Baetz M. The relationship between mood instability and suicidal thoughts. Archives of Suicide Research. 2015b; 19: 161-171.

26. Bowen R, Rahman $H$, Dong LY, Khalaj S, Baetz M, Peters EM, et al Suicidality in people with obsessive-compulsive symptoms or personality traits. Frontiers in Psychiatry. 2019; 9: 747. 